(A) Check for updates

Cite this: Food Funct., 2017, 8, 3239

\section{Chemical, nutritive composition and a wide range of bioactive properties of honey mushroom Armillaria mellea (Vahl: Fr.) Kummer}

\author{
Marina Kostić, (D) a Marija Smiljković, (DD a Jovana Petrović, (DD a Jasmina Glamočlija, (iD a \\ Lillian Barros, (D) b Isabel C. F. R. Ferreira, (ID b Ana Ćirić (ID *a and Marina Soković (ID *a
}

\begin{abstract}
A. mellea fruiting bodies collected from nature were chemically characterized and shown to be rich in carbohydrates ( $81.25 \mathrm{~g}$ per $100 \mathrm{~g} \mathrm{dw}$ ), ash, fat and proteins ( $8.84 \mathrm{~g}$ per $100 \mathrm{~g} \mathrm{dw}, 1.97 \mathrm{~g}$ per $100 \mathrm{~g} \mathrm{dw}$ and $1.81 \mathrm{~g}$ per $100 \mathrm{~g} \mathrm{dw}$, respectively). Mannitol was the main free sugar while malic acid was the most abundant organic acid. $\delta$-Tocopherol was the dominant form of tocopherols with $42.41 \mu \mathrm{g}$ per $100 \mathrm{~g} \mathrm{dw}$. Polyunsaturated fatty acids were predominant, followed by saturated and monounsaturated fatty acids. A methanolic extract prepared from these samples was tested for antioxidant, quorum sensing and antimicrobial assays, as well as for its cytotoxicity effects. The extract showed antimicrobial activity against all tested microorganisms, including Candida albicans. Furthermore, when tested at sub-MIC concentration, it showed reduction of virulence factors and biofilm formation against Pseudomonas aeruginosa. The extract also exhibited antioxidant activity and did not show toxicity against tumor and non-tumor cells. Due to the observed bioactive properties and compounds of the honey mushroom and its well-balanced nutrients, this mushroom emerges as an interesting functional food and a source of nutraceuticals with applications in different diseases based on antioxidant and antimicrobial effects.
\end{abstract}

Received 15th June 2017 Accepted 12th July 2017

DOI: $10.1039 / \mathrm{c} 7 f \circ 00887 \mathrm{~b}$

rsc.li/food-function logically valuable compounds (including medicinal), some of which showed significant antimicrobial, antioxidant, cytotoxic and other activities. ${ }^{4,5}$ This indicates their potential beneficial role as new active agents against the diseases of the modern era. ${ }^{6}$

Despite the progress in designing targeted biologically active compounds, an increased number of multiple drug resistant pathogenic microorganisms have become a serious global problem leading to multiple fatal outcomes. ${ }^{7}$ A possible solution to this problem may be the comprehension of the intercellular signaling pathway which is known as quorum sensing (QS). This phenomenon which serves for communication among bacteria includes the regulation of their gene expression, via releasing low molecular weight compounds, autoinducers, into the extracellular matrix where bacteria are immersed. ${ }^{8}$ Due to its important role in various bacterial regulatory processes (competence, sporulation, biofilm formation, etc.) it may serve as an important target when forming a strategy for the eradication of pathogenic microorganisms, including some of the potentially lethal opportunistic pathogens such as Pseudomonas aeruginosa and Candida albicans. ${ }^{9-11}$

$P$. aeruginosa is a Gram-negative pathogenic microorganism which can cause serious infections in immunocompromised patients, whereas in certain patients (suffering from cystic fibrosis and chronic obstructive pulmonary disorder, or those with exposed wounds) it is a significant cause of death. ${ }^{11,12}$

\footnotetext{
${ }^{a}$ Department of Plant Physiology, Institute for Biological Research "Siniša Stanković, University of Belgrade, Bulevar Despota Stefana 142, 11000 Belgrade, Serbia. E-mail: rancic@ibiss.bg.ac.rs, mris@ibiss.bg.ac.rs; Fax: +381 112078433; Tel: +381112078419

${ }^{b}$ Centro de Investigação de Montanha (CIMO), ESA, Instituto Politécnico de Bragança, Campus de Santa Apolónia, 5300-253 Bragança, Portugal
} 
Estimates of the Health Care system in the USA are that nearly 51000 nosocomial infections per year are caused by P. aeruginosa. Over $13 \%$ of these infections are multidrugresistant, with a mortality rate of nearly 400 deaths per year. ${ }^{13}$ As for C. albicans, this yeast is considered a member of the healthy human skin and mucosal surfaces, but under certain circumstances, it can manifest a broad spectrum of symptoms: from superficial to life-threatening systemic infections. ${ }^{14}$ Estimates indicate that various Candida species are the fourth most common isolated pathogens from patients with systemic infections. ${ }^{15}$ According to the World Health Organization data from 2014, nearly 13.3 million people in the world are affected with oral candidiasis, and nearly $90 \%$ of them are suffering from immunodeficiency diseases as well (for example HIV/AIDS). The mortality rate of some Candida strains is $35 \%$ depending on the type and organ affected with the infection. $^{16}$

Given these circumstances, where commercially available agents are not effective enough, and the number of people with a severely compromised immune system has increased, returning to naturally sourced substances seems like an adequate solution. Studies indicate that mushrooms have a profound effect on the pathogenic microorganisms inhibiting their growth. ${ }^{17}$ In addition, they act as immunostimulators, enhancing the activity of the individual's immune system giving them great pharmacological and medicinal potential. ${ }^{18}$

Armillaria mellea (Vahl: Fr.) Kummer, the honey mushroom, or zhen-mo in China, ${ }^{19}$ is an edible, medicinal mushroom widely distributed in the coniferous forests of the Northern Hemisphere. ${ }^{20}$ A. mellea was believed to be a highly polymorphic species complex, revealing approximately 40 described species with lifestyles that range from saprotrophic to pathogenic. ${ }^{21}$ It has been traditionally used in Chinese herbal medicine to treat headache, hypertension, epilepsy, insomnia, neurasthenia and many other disorders. ${ }^{19}$ Also, it has been proved to have an antihyperglycemic effect. ${ }^{22}$

In the present study, we report a comprehensive chemical analysis of A. mellea collected from Serbia, as well as some of its biological activities (including antioxidant, antimicrobial, antiquorum sensing and cytotoxicity). In addition, this study provides the first data on the capacity of its methanolic extract to interfere with quorum-sensing regulated functions (biofilm formation, pyocyanin production, bacterial motility), which might have great potential in the near future.

\section{Materials and methods}

\subsection{Standards and reagents}

The following reagents were purchased from Fisher Scientific (Lisbon, Portugal): acetonitrile 99.9\%, $n$-hexane 95\% and ethyl acetate $99.8 \%$ were of HPLC grade. The standard mixture (standard 47885-U) of fatty acid methyl ester (FAME, 37 Component FAME Mix) was purchased from Sigma (St Louis, MO, USA), as well as the rest of the individual fatty acid isomers, phenolic compounds ( $p$-hydroxybenzoic acid 99\% and cinnamic acid
99\%), (oxalic acid 98\%, D-(+)-malic acid $\geq 97.0 \%$, citric acid, $99 \%$ and fumaric acid $>98 \%$ ), sugars (D-mannitol $\geq 98 \%$ and D-trehalose 99\%) and Trolox (6-hydroxy-2,5,7,8-tetramethylchroman-2-carboxylic acid 97\%, used as a standard). Racemic tocol (HPLC, 98\%), $50 \mathrm{mg} \mathrm{mL}^{-1}$, and tocopherol standards were purchased from Matreya (Pleasant Gap, PA, USA). 2,2Diphenyl-1-picrylhydrazyl (DPPH, 99.6\%) was obtained from Alfa Aesar (Ward Hill, MA, USA). Mueller-Hinton agar (MH) and malt agar (MA) used for the cultivation of microorganisms were obtained from the Institute of Immunology and Virology, Torlak (Belgrade, Serbia). Dimethylsulfoxide (DMSO, 99.9\%) (Merck KGaA, Darmstadt, Germany) was used as a solvent. Methanol and other chemicals used for analyses were of analytical grade and purchased from common sources. Water was treated in a Milli-Q water purification system (TGI Pure Water Systems, USA), and sterilized for further use in the bioassays.

\subsection{Mushroom samples}

The fruiting bodies of $A$. mellea were collected from the oak trunks at mountain Divčibare (region of Western Serbia) during October 2015, and authenticated by Jasmina Glamočlija, Principal Research Fellow at the Institute for Biological Research "Siniša Stanković, University of Belgrade. A voucher specimen was deposited at the Fungal Collection Unit of the Mycological Laboratory, under the code Am-0112015. Fresh and cleaned fruiting bodies were randomly divided and freezed at $-20{ }^{\circ} \mathrm{C}$, after which they were lyophilized (LH Leybold, Lyovac GT2, Frenkendorf). After reaching constant mass, they were milled into a fine powder using a laboratory blender, mixed to obtain a homogeneous sample, and kept at $4{ }^{\circ} \mathrm{C}$, untill further analysis.

All determinations were carried out three times (three separate samplings) and in triplicate. Values were averaged and reported along with the standard deviation (SD).

\subsection{Chemical characterization}

2.3.1. Nutritional composition. Moisture, proteins, fat, carbohydrates and ash were determined using procedures approved by the AOAC (2016). ${ }^{23}$ The crude protein content $(N \times$ 4.38) was estimated by the macro-Kjeldahl method; the crude fat was determined by extracting a known weight of the powdered sample with petroleum ether, using a Soxhlet apparatus; the ash content was determined by incineration at $600 \pm 15^{\circ} \mathrm{C}$. Total carbohydrates were calculated by difference. The energy contribution was calculated according to the following equation: Energy $(\mathrm{kcal})=4 \times(\mathrm{g}$ protein $+\mathrm{g}$ carbohydrate $)+$ $9 \times(\mathrm{g}$ fat $)$.

2.3.2. Hydrophilic compounds. Free sugars were determined using the fruiting body and analyzed by using a High Performance Liquid Chromatography (HPLC) system, which consisted of an integrated system with a pump (Knauer, Smartline system 1000, Berlin, Germany), a degasser system (KnauerSmartline manager 5000, Berlin, Germany) and an auto-sampler (AS-2057 Jasco, Easton, MD, USA), coupled to a refraction index detector (RIdetector KnauerSmartline 2300, 
Berlin, Germany). The extraction procedure was performed according to Barros et al. (2008) ${ }^{24}$ whereas their identification was made by comparing the relative retention times of sample peaks with standards. The obtained data were analyzed using Clarity 2.4 Software (DataApex, Prague, Czech Republic). Quantification was based on the RI signal response of each standard, using the internal standard (IS, raffinose) method and by using calibration curves obtained from the commercial standards of each compound. The results were expressed in $\mathrm{g}$ per $100 \mathrm{~g}$ of dry weight.

Organic acids were determined using the fruiting body and analyzed by ultra-fast liquid chromatography (UFLC, Shimadzu 20A series, Kyoto, Japan) coupled with a photodiode array detector (PDA). Following the procedure described by Barros et al. (2013), ${ }^{25}$ organic acids were quantified by comparing the area of their peaks recorded at $\lambda=215 \mathrm{~nm}$, with the calibration curves obtained from the commercial standards of each compound. The results were expressed in $\mathrm{g}$ per $100 \mathrm{~g}$ of dry weight.

Phenolic acids were present in the fruiting body and chromatographic analysis was performed as previously described by Bessada et al. (2016). ${ }^{26}$ For double online detection, $280 \mathrm{~nm}$ was used as the preferred wavelength for DAD and a mass spectrometer (MS) was used. MS detection was performed in negative mode, using a Linear Ion Trap LTQ XL mass spectrometer (ThermoFinnigan, San Jose, CA, USA) equipped with an ESI source. The identification of the phenolic acids was performed using standard compounds, when available, by comparing their retention times, UV-vis and mass spectra; and also, by comparing the obtained information with available data reported in the literature. For quantitative analysis, a calibration curve for each available phenolic standard was constructed based on the UV signal and the results were expressed as $\mu \mathrm{g}$ per $100 \mathrm{~g}$ of dry weight.

2.3.3. Lipophilic compounds. Fatty acids were determined, after extraction using the fruiting body and transesterification procedures described by Barros et al. (2008), ${ }^{24}$ performed with a gas chromatograph (DANI 1000, Milan, Italy) equipped with a split/splitless injector and a flame ionization detector (GC-FID). The identification of the fatty acids was achieved by comparing the relative retention times of FAME peaks from samples with standards. The results were recorded and processed using CSW 1.7 software (DataApex 1.7, Prague, Czech Republic) and expressed in relative percentage of each fatty acid.

Tocopherols were extracted using the fruiting body, following the procedure described by Heleno et al. (2010), ${ }^{27}$ and determined by HPLC (equipment described above, for sugar analysis) and a fluorescence detector (FP-2020; Jasco, Easton, MD, USA) programmed for excitation at $\lambda=290 \mathrm{~nm}$ and emission at $\lambda=330 \mathrm{~nm}$. The compounds were identified by chromatographic comparison with authentic standards. Quantification was based on the fluorescence signal response of each standard, using the IS (tocol) method and by using calibration curves obtained from the commercial standards of each compound. The results were expressed in $\mu \mathrm{g}$ per $100 \mathrm{~g}$ of dry weight.

\subsection{Preparation of the methanolic extracts}

The methanolic extracts of the honey mushroom were obtained as follows: approximately $10 \mathrm{~g}$ of ground mushroom powder was extracted with $340 \mathrm{~mL}$ of methanol (Carlo Erba reagents, Italy) overnight at $-20{ }^{\circ} \mathrm{C}$, after which the suspension was sonicated for 15 minutes, centrifuged at $3100 \mathrm{~g}$, and subsequently filtered through Whatman No. 4 paper. The process was followed by further extraction of the residue using an ultrasonic bath $(3 \times 15 \mathrm{~min})$, with three additional portions of methanol $(3 \times 100 \mathrm{~mL})$, and filtration of the extract through Whatman No. 4 paper. Combined methanolic extracts were evaporated at $40{ }^{\circ} \mathrm{C}$ on a rotary evaporator (Büchi R-210 rotary evaporator, Flawil, Switzerland) to dryness. The methanolic extracts were redissolved in (i) methanol (final concentration, $20 \mathrm{mg} \mathrm{mL}^{-1}$ ) for antioxidant activity evaluation, (ii) $30 \%$ ethanol (final concentration, $30 \mathrm{mg} \mathrm{mL}^{-1}$ ) for antimicrobial assays, or (iii) water (final concentration, $8 \mathrm{mg} \mathrm{mL}^{-1}$ ) for antitumour activity evaluation.

\subsection{Evaluation of the antioxidant activity}

2.5.1. General. The antioxidant activity of the extracts was evaluated by different in vitro assays using successive dilutions prepared from the stock solution. The sample concentrations providing $50 \%$ of antioxidant activity or 0.5 of absorbance $\left(\mathrm{EC}_{50}\right)$ were calculated from the graphs of antioxidant activity percentages (DPPH, $\beta$-carotene/linoleate and TBARS assays) or absorbance at $690 \mathrm{~nm}$ (ferricyanide/Prussian blue assay) against sample concentrations. ${ }^{28}$ A commercially available agent, Trolox, was used as the standard.

2.5.2. Folin-Ciocalteu assay. The extract solution $(1 \mathrm{~mL})$ was mixed with the Folin-Ciocalteu reagent $(5 \mathrm{~mL}$, previously diluted with water $1: 10, \mathrm{v} / \mathrm{v})$ and sodium carbonate $\left(75 \mathrm{~g} \mathrm{~L}^{-1}\right.$, $4 \mathrm{~mL}$ ). The tubes were mixed vigorously by vortexing for $15 \mathrm{~s}$ and allowed to stand for $30 \mathrm{~min}$ at $+40{ }^{\circ} \mathrm{C}$ for color development, followed by the measurement of the absorbance at $765 \mathrm{~nm}$ (Analytikjena spectrophotometer; Jena, Germany). Gallic acid was used to obtain the standard curve. The reduction of the Folin-Ciocalteu reagent by the samples was expressed in $\mathrm{mg}$ of gallic acid equivalents (GAE) per $\mathrm{g}$ of extract.

2.5.3. Reducing power or ferricyanide/Prussian blue assay. Briefly, the extract solutions with different concentrations $(0.5 \mathrm{~mL})$ were mixed with sodium phosphate buffer $(200 \mathrm{mmol}$ $\left.\mathrm{L}^{-1}, \mathrm{pH} 6.6,0.5 \mathrm{~mL}\right)$ and potassium ferricyanide $(1 \% \mathrm{w} / \mathrm{v}$, $0.5 \mathrm{~mL}$ ). The mixture was incubated at $+50{ }^{\circ} \mathrm{C}$ for $20 \mathrm{~min}$, and trichloroacetic acid $(10 \% \mathrm{w} / \mathrm{v}, 0.5 \mathrm{~mL})$ was added. The mixture $(0.8 \mathrm{~mL})$ was poured in a 48 -well plate. The procedure was repeated with deionised water $(0.8 \mathrm{~mL})$ and ferric chloride $(0.1 \% \mathrm{w} / \mathrm{v}, 0.16 \mathrm{~mL})$, after which the absorbance was measured at $690 \mathrm{~nm}$ using an ELX800 microplate reader (Bio-Tek Instruments, Inc.; Winooski, USA).

2.5.4. DPPH radical-scavenging activity assay. The reaction mixture consisting of $30 \mu \mathrm{L}$ of the extract solutions and $270 \mu \mathrm{L}$ of methanol containing DPPH radicals $\left(6 \times 10^{-5} \mathrm{~mol} \mathrm{~L}^{-1}\right)$ was poured in a 96 well-plate. The mixture was left to stand in the 
dark for $30 \mathrm{~min}$, and the absorption was measured at $515 \mathrm{~nm}$ using a microplate reader (Bio-Tek Instruments, Inc., Winooski, VT, USA). ${ }^{29}$ The radical scavenging activity (RSA) was calculated as a percentage of DPPH discolouration using the equation: $\% \mathrm{RSA}=\left[\left(A_{\mathrm{DPPH}}-A_{\mathrm{S}}\right) / A_{\mathrm{DPPH}}\right] \times 100$, where $A_{\mathrm{S}}$ is the absorbance of the solution containing the sample and $A_{\mathrm{DPPH}}$ is the absorbance of the DPPH solution.

2.5.5. Inhibition of $\beta$-carotene bleaching or $\beta$-carotene/ linoleate assay. A solution of $\beta$-carotene was prepared by dissolving $\beta$-carotene $(2 \mathrm{mg})$ in chloroform $(10 \mathrm{~mL})$. Two millilitres of this solution were pipetted into a round-bottom flask. The chloroform was removed at $40{ }^{\circ} \mathrm{C}$ under vacuum and linoleic acid (40 mg), Tween 80 emulsifier (400 mg), and distilled water $(100 \mathrm{~mL})$ were added to the flask with vigorous shaking. Aliquots $(4.8 \mathrm{~mL})$ of this emulsion were transferred into test tubes containing $0.2 \mathrm{~mL}$ of a range of concentrations of the extract. The tubes were shaken and incubated in a water bath at $50{ }^{\circ} \mathrm{C}$. The zero time absorbance was measured at $470 \mathrm{~nm}$, immediately after the emulsion was added to each tube. ${ }^{28}$ $\beta$-Carotene bleaching inhibition was calculated using the following equation: (Absorbance after $2 \mathrm{~h}$ of assay/initial absorbance) $\times 100$.

2.5.6. Thiobarbituric acid reactive substances (TBARS) assay. Porcine (Sus scrofa) brains were obtained from officially slaughtered animals, dissected, and homogenized with a Polytron homogenizer in ice cold Tris-HCl buffer $(20 \mathrm{mM}, \mathrm{pH}$ 7.4) to produce a $1: 2 \mathrm{w} / \mathrm{v}$ brain tissue homogenate. The homogenate was centrifuged at $3000 \mathrm{~g}$ for $10 \mathrm{~min}$, after which an aliquot $(100 \mu \mathrm{L})$ of the supernatant was incubated for $1 \mathrm{~h}$ at $37^{\circ} \mathrm{C}$ with $200 \mu \mathrm{L}$ samples of a range of concentrations of the extract in the presence of $\mathrm{FeSO}_{4}(10 \mathrm{mM} ; 100 \mu \mathrm{L})$ and ascorbic acid $(0.1 \mathrm{mM} ; 100 \mu \mathrm{L})$. The reaction was stopped with the addition of trichloroacetic acid $(28 \% \mathrm{w} / \mathrm{v}, 500 \mu \mathrm{L})$, followed by thiobarbituric acid (TBA, 2\%, w/v, $380 \mu \mathrm{L}$ ). The mixture was then heated for $20 \mathrm{~min}$ at $80{ }^{\circ} \mathrm{C}$. Centrifugation at $3000 \mathrm{~g}$ for $10 \mathrm{~min}$ was performed in order to remove the precipitated protein, whereas the color intensity of the malondialdehyde (MDA)-TBA complex in the supernatant was measured by its absorbance at $532 \mathrm{~nm} .{ }^{29}$ The inhibition ratio (\%) was calculated using the following formula: Inhibition ratio $(\%)=$ $[(A-B) / A] \times 100 \%$, with $A$ and $B$ being the absorbance of the control and the sample solution, respectively.

\subsection{Evaluation of the antimicrobial activity}

2.6.1. Microorganisms and culture conditions. Gram-positive bacteria, Staphylococcus aureus (ATCC 6538), Bacillus cereus (clinical isolate), Listeria monocytogenes (NCTC 7973), and Micrococcus flavus (ATCC 10240), as well as the following Gramnegative bacteria: Pseudomonas aeruginosa (ATCC 27853), Escherichia coli (ATCC 35210), Salmonella typhimurium (ATCC 13311), and Enterobacter cloacae (ATCC 35030) were used in order to determine the potential antimicrobial activity of the extract. For antifungal assays, eight micromycetes were used: Aspergillus niger (ATCC 6275), Aspergillus ochraceus (ATCC 12066), Aspergillus versicolor (ATCC 11730), Aspergillus fumigatus (human isolate), Trichoderma viride (IAM 5061), Penicillium funiculosum (ATCC 36839), Penicillium ochrochloron (ATCC 9112), and Penicillium verrucosum var. cyclopium (food isolate). In addition, four strains of Candida albicans (all of which are clinical isolates) were tested for their susceptibility to the mushroom extract. Strains were isolated by rubbing a sterile cotton swab over the oral cavities of the patients at the Otorhinolaryngology clinic at Clinical Hospital Center Zvezdara, Belgrade, Serbia, and determined using CHROMagar plates (Biomerieux, France). C. albicans isolates were maintained on Sabouraud dextrose agar (Merck, Germany) at $4{ }^{\circ} \mathrm{C}$ and subcultured once a month. All the tested microorganisms are deposited at the Mycological Laboratory, Department of Plant Physiology, Institute for Biological Research "Siniša Stankovic", University of Belgrade. The minimum inhibitory (MIC), minimum bactericidal (MBC) and minimum fungicidal (MFC) concentrations were determined by a modified microdilution method. ${ }^{30}$

2.6.2. Antibacterial and antifungal assays. The minimum inhibitory and bactericidal/fungicidal concentrations (MICs, MBCs and MFCs) were determined using 96-well microdilution plates (Spectar Cacak, Cacak, Serbia) with a flat bottom. ${ }^{30,31}$ The bacterial suspension was adjusted with sterile saline to a concentration of $1.0 \times 10^{5} \mathrm{CFU} \mathrm{mL}^{-1}$. The methanolic extract of $A$. mellea was dissolved in $30 \%$ ethanol solution and added to Tryptic soy broth (TSB) medium (Torlak, Belgrade, Serbia). Afterward, the bacterial inoculum was added to this mixture in order to achieve the appropriate concentrations. The lowest concentrations without visible growth (under a binocular microscope) were defined as the concentrations that completely inhibited bacterial growth (MICs). The MBCs were determined by serial sub-cultivation of $10 \mu \mathrm{L}$ into microdilution plates containing $100 \mu \mathrm{L}$ of broth per well and further incubation for $24 \mathrm{~h}$. The lowest concentration with no visible growth was defined as the MBC, indicating 99.5\% killing of the original inoculum. Streptomycin (Sigma-Aldrich S6501, St Louis, MO, USA) and ampicillin (Sigma-Aldrich A9393, Germany) were used as positive controls $\left(1 \mathrm{mg} \mathrm{mL}^{-1}\right.$ in sterile physiological saline). As for the antifungal activity, the assay was performed in the following manner: fungal spores were washed from the surface of agar plates with sterile $0.85 \%$ saline containing $0.1 \%$ Tween $80(\mathrm{v} / \mathrm{v})$. The spore suspension was adjusted with sterile saline to a concentration of approximately $1.0 \times 10^{5}$ in a final volume of $100 \mu \mathrm{L}$ per well. The inoculum was stored at $4{ }^{\circ} \mathrm{C}$ for further use. Dilutions of the inoculum were cultured on solid malt agar to verify the absence of contamination and to check the validity of the inoculum. Minimum inhibitory concentration (MIC) determination was performed by a serial dilution technique using 96-well micro titer plates. The extract of A. mellea was dissolved in $30 \%$ ethanol and added to malt extract broth (MEB) (Torlak, Belgrade, Serbia), after which the appropriate concentrations of the fungal inocula were added. The lowest concentrations without visible growth (under a binocular microscope) were defined as MICs. The fungicidal concentrations (MFCs) were determined by serial subcultivation of $2 \mu \mathrm{L}$ of the well's content and further incubation for $72 \mathrm{~h}$ at $28^{\circ} \mathrm{C}$. The 
lowest concentration with no visible growth was defined as the MFC indicating $99.5 \%$ killing of the original inoculum. Commercially available antifungal agents, bifonazole (Srbolek, Belgrade, Serbia) and ketoconazole (Zorkapharma, Sabac, Serbia) were used as positive controls.

\subsection{Evaluation of the antiquorum (AQ) sensing activity}

2.7.1. Bacterial strains, growth media and culture conditions. The opportunistic pathogen microorganism P. aeruginosa PA01 (ATCC 27853) was routinely grown in LuriaBertani (LB) medium (1\% w/v NaCl, 1\% w/v Tryptone, 0.5\% w/v yeast extract) (Torlak, Belgrade, Serbia), with agitation (220 $\mathrm{rpm})$ at the appropriate temperature $\left(37^{\circ} \mathrm{C}\right)$.

2.7.2. Biofilm formation. A biofilm was grown as described previously by Drenkard, 2002. ${ }^{32}$ The inhibitory potential of 0.5 , 0.25 , and 0.125 of the original MIC value of the methanolic extract on the formation of the biofilm was tested on polystyrene flat-bottomed microdilution 96-well plates as described by Spoering and Lewis $(2001)^{33}$ with certain modifications. This method in particular is designed to determine whether the naturally sourced mushroom extract has the potential to disrupt the cell to cell communication of PAO1, thus influencing its growth and biofilm structure which provides a certain level of endurance and resistance to antifungal agents. To summarize, $100 \mu \mathrm{L}$ of the overnight culture of $P$. aeruginosa PAO1 was added to each well of the plates in the presence of $100 \mu \mathrm{L}$ subinhibitory concentrations (subMICs) of the extractor $100 \mathrm{~mL}$ medium (control). Following incubation for $24 \mathrm{~h}$ at $37^{\circ} \mathrm{C}$, each well was washed twice with sterile PBS ( $\mathrm{pH} 7.4$ ), air dried (10 $\mathrm{min})$, and stained $(10 \mathrm{~min})$ with $0.1 \%$ crystal violet solution in order to determine and color the biofilm mass. The excess stain was washed with distilled water, and the plates were left to air dry $(10 \mathrm{~min})$. Then $200 \mu \mathrm{L}$ of $95 \%$ ethanol (v/v) (Carlo Erba reagents, Italy) was added to solubilize the residual color of the biofilm cells $(10 \mathrm{~min})$. The content of the wells was homogenized and the absorbance at $\lambda=$ $625 \mathrm{~nm}$ was read on a Sunrise ${ }^{\mathrm{TM}}$-Tecan ELISA reader (Männedorf, Switzerland).

2.7.3. Twitching and flagella motility. After growing in the presence/absence of the mushroom extract overnight, the cells of $P$. aeruginosa PA01 were washed twice with sterile PBS and resuspended in PBS at $1 \times 10^{8} \mathrm{CFU} \mathrm{mL}^{-1}$ (OD of 0.1 at $660 \mathrm{~nm})$. The protocol was as follows: cells of $P$. aeruginosa were inoculated into nutrient agar plate with a sterile toothpick and incubated overnight at $37{ }^{\circ} \mathrm{C}$, and then they were incubated at room temperature $\left(+22^{\circ} \mathrm{C}\right)$ for an additional $48 \mathrm{~h}$. Edges of the colony and the motility zone were observed and measured under a light microscope, and described via several characteristics such as the color and the edge of the colony, diameter and the flagella shape. ${ }^{34}$ The subMICs of the tested extract were mixed with $10 \mathrm{~mL}$ of molten $\mathrm{LB}$ medium and poured immediately over the surface of a solidified LBA plate as an overlay. The plate was point inoculated with an overnight culture of PAO1 once the overlaid agar had solidified and incubated at $37{ }^{\circ} \mathrm{C}$ for 3 days. The extent of swimming was determined by measuring the area of the colony. ${ }^{35}$
2.7.4. Anti-QS against $P$. aeruginosa PA01 pyocyanin. The overnight culture of $P$. aeruginosa PA01 was diluted to $\mathrm{OD}_{600} \mathrm{~nm}$ to a value of 0.2 . The tested extract (dissolved as 0.5 MIC) was added to $P$. aeruginosa and incubated at $37^{\circ} \mathrm{C}$ for $24 \mathrm{~h}$. The suspension was vigorously mixed with chloroform (5 mL) (Centrochem, Belgrade, Serbia), followed by the addition of $0.2 \mathrm{M} \mathrm{HCl}$ (1 mL) (Zorkapharma, Sabac, Serbia). The absorbance of the extracted pink organic layer (which actually contains pyocyanin) was measured at $520 \mathrm{~nm}$ using a UV-visible spectrophotometer (UV1601, Shimadzu, Kyoto, Japan). ${ }^{36}$

\subsection{Evaluation of the cytotoxicity in tumor and non-tumor cells}

Five human tumor cell lines, MCF-7 (breast adenocarcinoma), NCI-H460 (non-small-cell lung cancer), HCT-15 (colon carcinoma), HeLa (cervical carcinoma) and HepG2 (hepatocellular carcinoma), were tested. Cells were routinely maintained as adherent cell cultures in RPMI-1640 medium containing 10\% heat-inactivated FBS (MCF-7, NCI-H460 and HCT-15) and $2 \mathrm{mM}$ glutamine, or in DMEM supplemented with $10 \% \mathrm{FBS}$, $2 \mathrm{mM}$ glutamine, $100 \mathrm{U} \mathrm{mL}^{-1}$ penicillin and $100 \mathrm{mg} \mathrm{mL} \mathrm{m}^{-1}$ streptomycin (HeLa and HepG2 cells) at $37^{\circ} \mathrm{C}$, in a humidified air incubator containing $5 \% \mathrm{CO}_{2}$. Each cell line was plated at an appropriate density $\left(7.5 \times 10^{3}\right.$ cells per well for MCF-7, NCI-H460 and HCT-15 and $1.0 \times 10^{4}$ cells per well for HeLa and HepG2) in 96-well plates and allowed to attach for $24 \mathrm{~h}$, after which they were treated for $48 \mathrm{~h}$ with the extract solutions. Subsequently, the adherent cells were fixed by adding cold 10\% trichloroacetic acid (TCA, $100 \mathrm{~mL}$ ) and incubated for $60 \mathrm{~min}$ at $4{ }^{\circ} \mathrm{C}$. The plates were then washed with deionized water and dried. Sulforhodamine B solution $(0.1 \%$ in $1 \%$ acetic acid, $100 \mathrm{~mL}$ ) was added and the plates were incubated further for $30 \mathrm{~min}$ at room temperature. The residual unbound SRB was removed by washing the plates with $1 \%$ acetic acid. After air drying, the bound SRB in plates was solubilized by adding $10 \mathrm{mM}$ Tris (200 mL, pH 7.4) and the absorbance was measured at $540 \mathrm{~nm}^{37}$

Regarding non-tumor cells, a cell culture, which was designated as PLP2, was prepared from a freshly harvested porcine liver obtained from a local slaughterhouse. Briefly, the liver tissues were rinsed in Hank's balanced salt solution (100 $\mathrm{U} \mathrm{mL}^{-1}$ penicillin and $100 \mathrm{mg} \mathrm{mL}^{-1}$ streptomycin), and divided into $1 \times 1 \mathrm{~mm}^{3}$ explants. Some of these explants were placed in $25 \mathrm{~cm}^{2}$ tissue flasks in Dulbecco's Modified Eagle's Medium (DMEM), supplemented with $10 \%$ fetal bovine serum, $2 \mathrm{mM}$ nonessential amino acids, $100 \mathrm{U} \mathrm{mL}^{-1}$ penicillin, and 100 $\mathrm{mg} \mathrm{mL}{ }^{-1}$ streptomycin and incubated at $37^{\circ} \mathrm{C}$ under a humidified atmosphere containing $5 \% \mathrm{CO}_{2}$. Cultivation of the cells was continued by direct monitoring every 2-3 days using a phase contrast microscope. Before confluence, the cells were subcultured and plated in 96-well plates at a density of $1.0 \times 10^{4}$ cells per well, and cultivated in a DMEM medium with $10 \% \mathrm{FBS}$, $100 \mathrm{U} \mathrm{mL}^{-1}$ penicillin and $100 \mathrm{mg} \mathrm{mL}^{-1}$ streptomycin. $^{38}$ The cells were treated for $48 \mathrm{~h}$ with the different diluted sample solutions, and the same procedure described for the SRB assay 
was followed. The results were expressed in $\mathrm{GI}_{50}$ values. Ellipticine was used as the positive control.

\section{Results and discussion}

\subsection{Chemical composition of Armillaria mellea}

The chemical profiling of the honey mushroom was conducted on several occasions targeting different compounds. However, to the best of the author's knowledge, this is the first study on the chemical composition of $A$. mellea fruiting bodies originating from Serbia. The results regarding nutritional values, and hydrophilic and lipophilic compounds are presented in Table 1. Carbohydrates were the most abundant compounds with $81.25 \mathrm{~g}$ per $100 \mathrm{~g}$ dw, followed by ash $(8.84 \mathrm{~g}$ per 100 $\mathrm{g} \mathrm{dw}$ ), fat (1.97 $\mathrm{g}$ per $100 \mathrm{~g} \mathrm{dw}$ ) and proteins (1.81 g per 100 $\mathrm{g} \mathrm{dw}$ ). With an energy value of $374.52 \mathrm{kcal}$ per $100 \mathrm{~g} \mathrm{dw}$, it represents a very good low-fat food which should be used on a regular basis. This is in concordance with previous reports on mushroom's nutritional composition. ${ }^{39}$

The presence of sugars, organic acids and phenolic compounds was confirmed. Mannitol was the most abundant sugar (5.92 g per $100 \mathrm{~g} \mathrm{dw}$ ), while trehalose was less present in the sample ( $1.72 \mathrm{~g}$ per $100 \mathrm{~g} \mathrm{dw})$. On the other hand, D-xylose, D-glucose and D-galactose were detected by GC/MS from chinese A. mellea in a study carried out by Zhang et al. (2015). ${ }^{19}$ Regarding organic acids, malic acid was found in $5.64 \mathrm{~g}$ per $100 \mathrm{~g} \mathrm{dw}$, while citric, fumaric and oxalic acids were detected in much lower amounts $(0.57 \mathrm{~g}$ per $100 \mathrm{~g} \mathrm{dw}, 0.52$ $\mathrm{g}$ per $100 \mathrm{~g} \mathrm{dw}$ and $0.03 \mathrm{~g}$ per $100 \mathrm{~g}$ dw, respectively). These results are important since organic acids present in natural matrices are involved in the reduction of oxidative stress.

In addition, phenolic compounds which have been related to antioxidant and antimicrobial activities were also observed in the sample: $p$-hydroxybenzoic acid $36.71 \mu \mathrm{g}$ per $100 \mathrm{~g} \mathrm{dw}$ and cinnamic acid $72.89 \mu \mathrm{g}$ per $100 \mathrm{~g} \mathrm{dw}$.

Lipophilic compounds, including fatty acids and tocopherols, were characterized (Table 2). Twenty-five fatty acids were identified, both saturated and unsaturated, with the prevalence of linoleic (63.80\%), oleic (15.47\%) and palmitic $(12.63 \%)$ acids. Polyunsaturated acids, which are considered beneficial to human health, have been found to be predominant in $A$. mellea with $64.12 \%$, followed by saturated fatty acids $(18.42 \%)$ and monounsaturated fatty acids $(17.47 \%)$. Previous reports on the $A$. mellea fatty acid composition revealed the presence of 17 of these fatty acids. ${ }^{40}$

Tocopherols are powerful natural antioxidants present in natural sources usually as a mixture of four isomers (namely $\alpha-, \beta-, \gamma-$, and $\delta$-tocopherol). ${ }^{29} \delta$-Tocopherol was the only isoform present in the sample $(42.41 \mu \mathrm{g}$ per $100 \mathrm{~g} \mathrm{dw})$.

\subsection{Antioxidant activity of Armillaria mellea methanolic extract}

The imbalance between the production and neutralization of reactive oxidative species within the organisms is reflected through the accumulation of damaged cell structures (i.e. cell

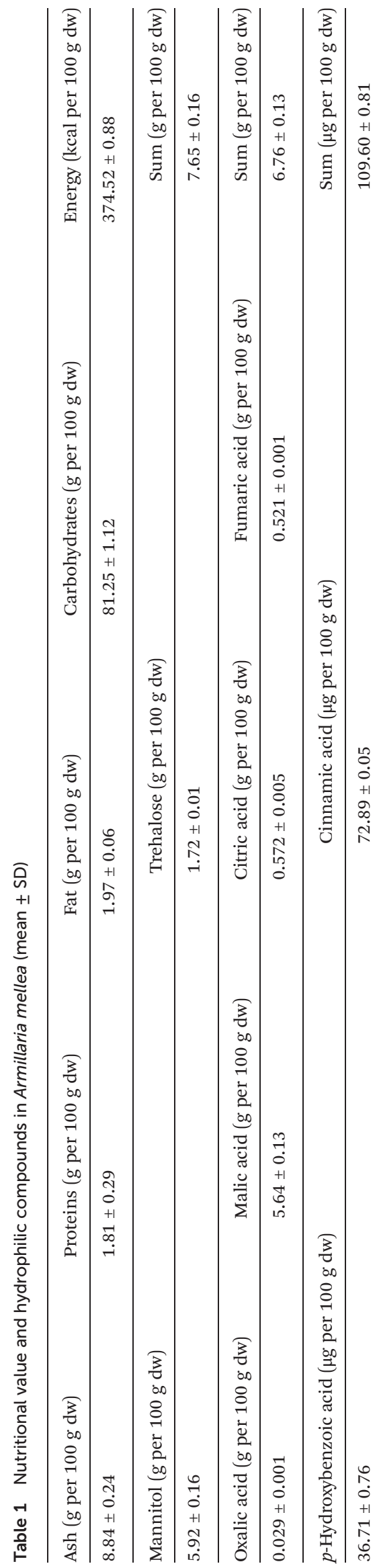


Table 2 Lipophilic compounds in Armillaria mellea (mean \pm SD)

\section{Fatty acids}

C6:0 Caproic acid

C8:0 Caprylic acid

C10:0 Capric acid

C12:0 Lauric acid

C14:0 Myristic acid

C14:1 Myristoleic acid

C15:0 Pentadecanoic acid

C16:0 Palmitic acid

C16:1 Palmitoleic acid

C17:0 Heptadecanoic acid

C18:0 Stearic acid

C18:1n9 Oleic acid

C18:2n6 Linoleic acid

C18:3n3 Linolenic acid

C20:0 Arachidic acid

C20:1 cis-11-Eicosenoic acid

C20:2 cis-11,14-Eicosadienoic acid

C20:3n 3 + C21:0 cis-11,14,17-Eicosatrienoic

acid + heneicosanoic acid

C20:5n 3 cis-5,8,11,14,17-Eicosapentaenoic acid

C22:0 Behenic acid

C22:1n9 Erucic acid

C23:0 Tricosanoic acid

C24:0 Lignoceric acid

C24:1 Ceramide

Total SFA ( $\%$ of total FA)

Total MUFA (\% of total FA)

Total PUFA ( $\%$ of total FA)

\section{Tocopherols}

\begin{tabular}{ll}
\hline$\alpha$-Tocopherol & $\mathrm{Nd}$ \\
$\beta$-Tocopherol & $\mathrm{Nd}$ \\
$\gamma$-Tocopherol & $\mathrm{Nd}$ \\
$\delta$-Tocopherol & $42.41 \pm 4.10$ \\
Sum $(\mu \mathrm{g}$ per $100 \mathrm{~g} \mathrm{dw})$ & $42.41 \pm 4.10$
\end{tabular}

SFA, saturated fatty acids; FA, fatty acids; MUFA, monounsaturated fatty acids; PUFA, polyunsaturated fatty acids; dw, dry weight. nd - not detected.

membrane, proteins) that lead to oxidative stress. Mushrooms have been described as a source of natural antioxidant compounds. ${ }^{41}$ In the present study, the antioxidant activity of the mushroom methanolic extract was evaluated through its reducing power, radical scavenging activity and lipid peroxidation inhibition. In the Folin-Ciocalteu assay (which measures the reducing power of the extract in relation to the molybdenum ion present in the Folin-Ciocalteu reagent), higher values mean higher reducing power, whereas for other assays, the results are presented in $\mathrm{EC}_{50}$ values. These results indicate that higher values correspond to lower reducing potential (ferricyanide/Prussian blue) or antioxidant potential (DPPH scavenging activity, $\beta$ carotene/linoleate and TBARS). All the obtained data can be observed in Table 3 .

The honey mushroom methanolic extract possesses a significant antioxidant activity. This makes it a good candidate for ongoing research on the use of natural substances as antioxidant agents in the food industry. In addition, it may very well increase the amount of consumed mushrooms per individual in order to reduce oxidative stress. The highest antioxidant effect was measured in ferricyanide/Prussian blue $\left(\mathrm{EC}_{50}=1.84 \mathrm{mg} \mathrm{mL}{ }^{-1}\right)$, followed by $\beta$-carotene/linoleate $\left(\mathrm{EC}_{50}=\right.$ $\left.3.29 \mathrm{mg} \mathrm{mL}^{-1}\right)$, DPPH scavenging activity $\left(\mathrm{EC}_{50}=4.27 \mathrm{mg} \mathrm{mL}^{-1}\right)$ and TBARS inhibition $\left(\mathrm{EC}_{50}=6.19 \mathrm{mg} \mathrm{mL}^{-1}\right)$ assays. Previous results on the antioxidant activity of the A. mellea ethanolic extract obtained from its mycelia by the DPPH method showed the lowest scavenging activity $(2,85 \%) .{ }^{42}$ Zavastin et al. reported the $\mathrm{EC}_{50}$ values of $452.6 \pm 2.7 \mu \mathrm{g} \mathrm{ml} \mathrm{ml}^{-1}$ (DPPH method) for the hydromethanolic extract obtained from the fruiting body of $A$. mellea, and the $\mathrm{EC}_{50}$ values for the ethanolic extract were not determined. ${ }^{22}$

\subsection{Antimicrobial activity of Armillaria mellea methanolic extract}

The results of antimicrobial activity indicate that the honey mushroom methanolic extract possesses very good antifungal activity, slightly better than its antibacterial activity. The presence of the microbicidal effect on both pathogenic bacterial and fungal species indicates the possible presence of compounds with a broad spectrum of activity. The antibacterial activity was in the range of $3.12-15.00 \mathrm{mg} \mathrm{mL}^{-1}$ for inhibitory activity (MIC values), and 6.25-25.00 $\mathrm{mg} \mathrm{mL}^{-1}$ for bactericidal activity (MBC), depending on the species. The most susceptible strains of bacteria were $S$. aureus and $P$. aeruginosa, which may be of significance, since these bacteria usually develop resistance to commercially available agents. ${ }^{43,44}$ The most resistant bacteria in the survey were L. monocytogenes, $S$. typhimurium and E. coli with $\mathrm{MBC}$ values of 12.5 and $15.00 \mathrm{mg} \mathrm{mL}^{-1}$. The results of the antifungal activity were slightly better that those of the antibacterial activity (Table 4). A. fumigatus, an opportunistic pathogen was proved to be the most resilient to the activity of the

Table 3 Antioxidant activity of Armillaria mellea methanolic extract (mean \pm SD)

\begin{tabular}{|c|c|c|c|c|}
\hline \multicolumn{2}{|l|}{ Reducing power } & \multirow{2}{*}{$\begin{array}{l}\text { Scavenging activity } \\
\text { DPPH scavenging activity } \\
\left(\mathrm{EC}_{50} ; \mathrm{mg} \mathrm{mL}^{-1}\right)\end{array}$} & \multicolumn{2}{|c|}{ Lipid peroxidation inhibition } \\
\hline $\begin{array}{l}\text { Folin-Ciocalteu } \\
\text { (mg GAE per g extract) }\end{array}$ & $\begin{array}{l}\text { Ferricyanide/Prussian } \\
\text { blue }\left(\mathrm{EC}_{50} ; \mathrm{mg} \mathrm{mL}^{-1}\right)\end{array}$ & & $\begin{array}{l}\beta \text {-Carotene } \\
\left(\mathrm{EC}_{50} ; \mathrm{mg} \mathrm{mL}^{-1}\right)\end{array}$ & $\begin{array}{l}\text { TBARS } \\
\left(\mathrm{EC}_{50} ; \mathrm{mg} \mathrm{mL}^{-1}\right)\end{array}$ \\
\hline $22.39 \pm 0.75$ & $1.84 \pm 0.01$ & $4.27 \pm 0.48$ & $3.29 \pm 0.52$ & $6.19 \pm 0.47$ \\
\hline
\end{tabular}

The antioxidant activity was expressed as $\mathrm{EC}_{50}$ values, which means that higher values correspond to lower reducing power or antioxidant potential. $\mathrm{EC}_{50}$ : Extract concentration corresponding to $50 \%$ of antioxidant activity or 0.5 of absorbance in reducing power assay. Trolox $\mathrm{EC}_{50}$ values: $18 \pm 1 \mu \mathrm{g} \mathrm{mL} \mathrm{g}^{-1}$ (reducing power), $41 \pm 1 \mu \mathrm{g} \mathrm{mL} \mathrm{m}^{-1}$ (DPPH scavenging activity), $41.7 \pm 0.3 \mu \mathrm{g} \mathrm{mL} \mathrm{m}^{-1}$ ( $\beta$-carotene bleaching inhibition) and $23 \pm 1 \mu \mathrm{g} \mathrm{mL}^{-1}$ (TBARS inhibition). 
Table 4 Antimicrobial activity $\left(\mathrm{mg} \mathrm{mL}^{-1}\right)$ of Armillaria mellea methanolic extract (mean $\pm \mathrm{SD}$ )

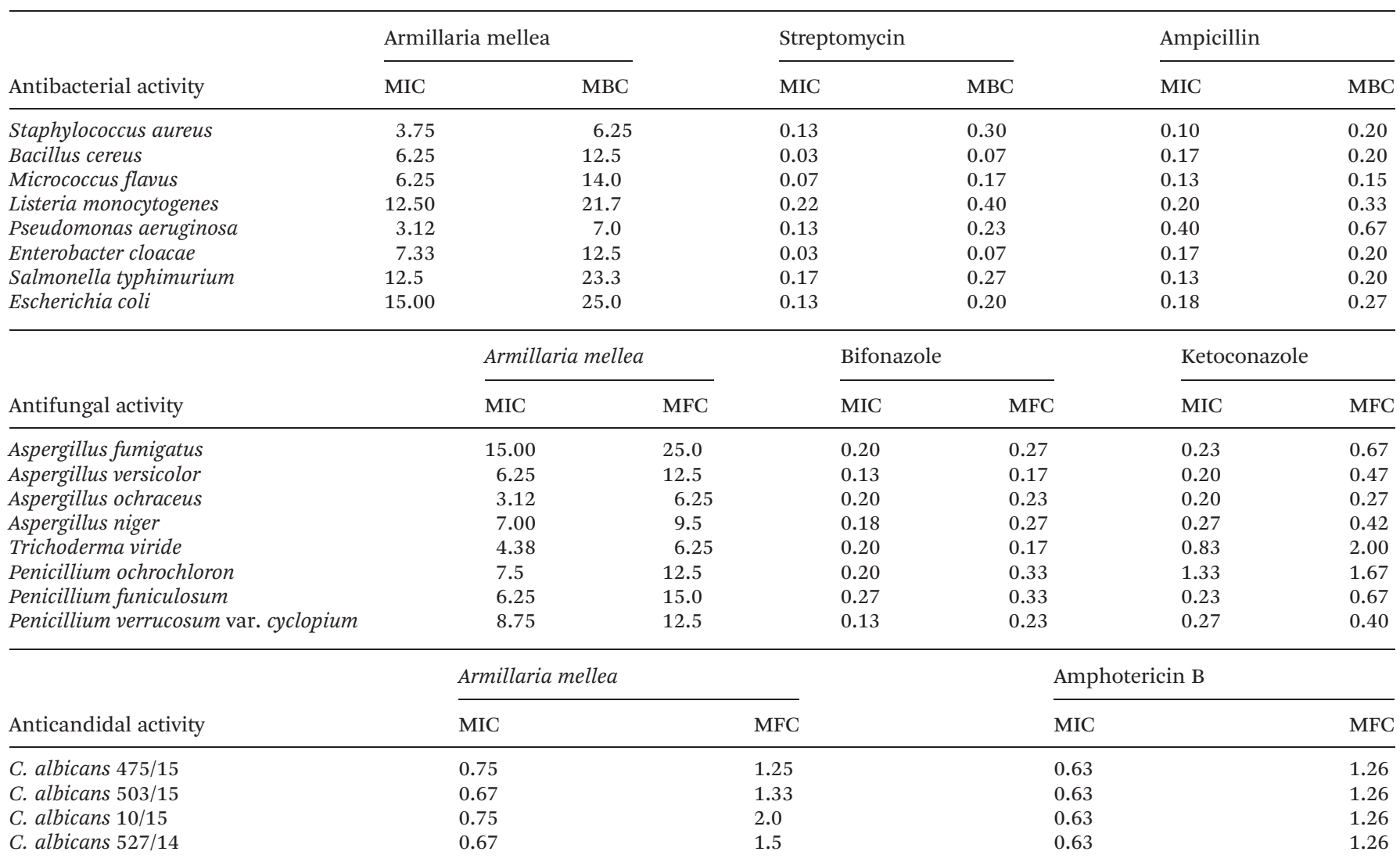

honey mushroom extract. Commercially available antimicrobial agents, streptomycin and ampicillin for antibacterial activity and bifonazole and ketoconazole for antifungal activity, proved to be more effective against the tested microorganisms than the methanolic extract, but taking into account the adverse effects of these agents on the overall health of individuals, the activity of naturally sourced products is of great importance. There are available literature data indicating the antimicrobial activity of the ethanolic extracts of A. mellea. Kalyoncu et al. $(2010)^{42}$ in their study confirmed the antimicrobial activity of the ethanolic extract of honey mushroom mycelia using the disk diffusion method against Gram-negative bacteria (with IZD-Inhibition Zone Diameter in the range of 8.00-10.00 $\mathrm{mm}$ ), but with no activity against Gram-positive bacteria. In comparison to this relatively weak activity of mycelia, a study conducted by Alves et al. $(2012)^{45}$ with the ethanolic extract of fruiting bodies collected in Portugal showed a significant microbicidal effect. This was confirmed against E. coli, S. aureus, Mycobacterium smegmatis and Sporothrix schenkii as well. ${ }^{46}$

To the best of the author's knowledge, there are no previous reports on the anticandidal activity of $A$. mellea extracts. In the present study, four strains of $C$. albicans were tested for their susceptibility to the methanolic extract, and the results indicate a rather uniform activity of the extract to selected pathogens of clinical importance (Table 4).

\subsection{Antiquorum sensing and antibiofilm formation activity of Armillaria mellea methanolic extract}

In the present study we have demonstrated that AQ sensing compounds disrupted bacterial biofilms and made the bacteria more susceptible to different antibiotics. In addition, these compounds were also able to reduce bacterial virulence factors. The effect of the $A$. mellea methanolic extract on the inhibition of $P$. aeruginosa biofilm formation was tested with 0.1 (0.5 MIC), 0.05 (0.25 MIC) and $0.025 \mathrm{mg} \mathrm{mL}^{-1}$ (0.125 MIC) of the previously determined MICs. Table 5 shows that the tested extract inhibits the formation of biofilms more effectively than antibiotics, especially at 0.5 MIC.

The initiation of biofilm formation by $P$. aeruginosa depends on two cell-associated structures: the flagellum (responsible for swarming motility) and type IV pili (respon-

Table 5 Percentage of inhibition of Pseudomonas aeruginosa biofilm formation using Armillaria mellea methanolic extract (mean \pm SD)

\begin{tabular}{llcc}
\hline & $0.5 \mathrm{MIC}$ & $0.25 \mathrm{MIC}$ & $0.125 \mathrm{MIC}$ \\
\hline Armillaria mellea & 69.18 & 45.89 & 17.01 \\
Streptomycin & 50.70 & 29.02 & 11.37 \\
Ampicillin & 30.86 & 43.54 & 7.85
\end{tabular}

Biofilm formation values were calculated as: (mean A620 control well) - (mean A620 treated well)/(mean A620 control well) $\times 100$. 


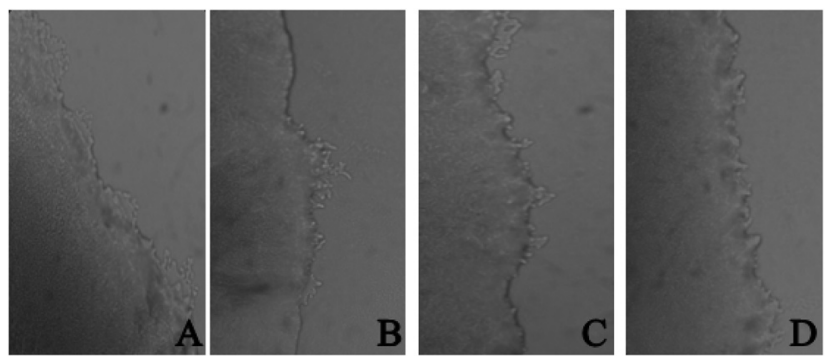

Fig. 1 Light microscopy images of the colony edges of Pseudomonas aeruginosa in twitching motility, grown in the presence or absence of Armillaria mellea extract at a concentration of 0.5 MIC. The colonies from the bacteria grown without the extract, control (A); Pseudomonas aeruginosa colony in the presence of streptomycin (B) and in the presence of ampicillin (C); Pseudomonas aeruginosa colony in the presence of Armillaria mellea methanolic extract (D); magnification: $(A-D) \times 100$.

sible for twitching motility). ${ }^{47,48}$ Therefore, the aim of our study was to determine whether the A. mellea extract can influence either one or both types of motilities. The extract insufficiently reduced the twitching motility of $P$. aeruginosa (Fig. 1), whereas the control (culture of PA01 without the extract or antibiotics) presented a rough appearance displaying irregular colony edges and a hazy zone surrounding the colony (Fig. 1). The results of the anti-QS activity of the tested extract and of antibiotics can be observed in terms of the colony diameter and its edges (Table 6). At sub-MIC concentrations, the diameter of the tested colonies was measured, indicating the most prominent activity of the commercially available therapeutic agents, followed by the activity of the mushroom extract. In comparison with the control, both streptomycin and A. mellea extract showed slightly reduced flagella (Fig. 1), while ampicillin did not affect the reduction of flagella at all (Fig. 1). In addition, the mushroom extract changed the color of the colony from green to brown.

It is known that $P$. aeruginosa produces a number of virulence factors, and one of them is pyocyanin which is considered a virulence factor responsible for antimicrobial resistance. $^{49}$ To quantify the QS inhibitory activity of the extract against pyocyanin production, a flask assay was used. The tested methanolic extract exhibited inhibitory activity toward the pyocyanin production in the tested concentration (0.5 MIC). The extract showed higher reduction (38.47\%) of the

Table 6 Twitching and motility activity of Armillaria mellea methanolic extract at MIC $0.5 \mathrm{mg} \mathrm{mL}^{-1}($ mean \pm SD)

\begin{tabular}{|c|c|c|c|}
\hline Agents & $\begin{array}{l}\text { Colony diameter } \\
(\text { mean } \pm \mathrm{SD})\end{array}$ & $\begin{array}{l}\text { Colony } \\
\text { color }\end{array}$ & $\begin{array}{l}\text { Colony edge on } \\
\text { the microscope }\end{array}$ \\
\hline Control P.a. $10^{9}$ & $11.33 \pm 1.15$ & Green & Regular flagella \\
\hline Streptomycin & $9.67 \pm 0.58$ & Light brown & $\begin{array}{l}\text { Slightly reduced } \\
\text { flagella }\end{array}$ \\
\hline Ampicillin & $10.33 \pm 1.53$ & Light brown & Regular flagella \\
\hline Armillaria mellea & $10 \pm 2.00$ & Brown & $\begin{array}{l}\text { Slightly reduced } \\
\text { flagella }\end{array}$ \\
\hline
\end{tabular}

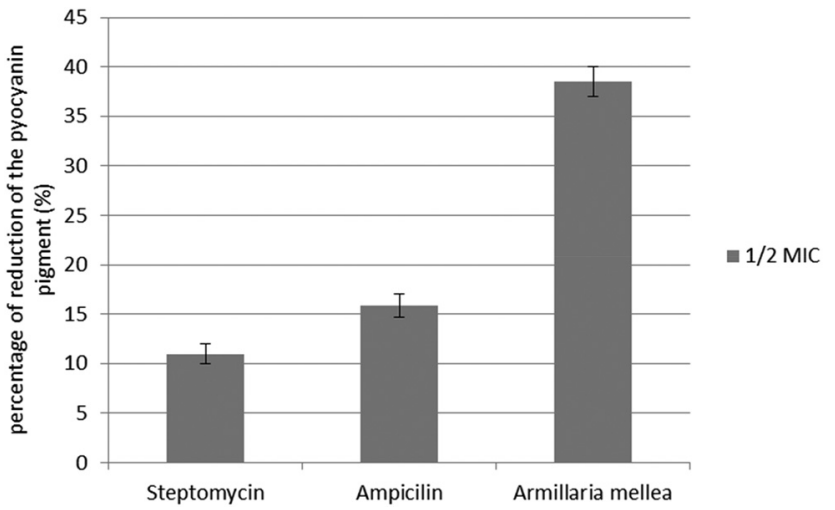

Fig. 2 Reduction of the pyocyanin pigment by Armillaria mellea extract.

pigment than streptomycin (10.96\%) and ampicillin (15.84\%) (Fig. 2).

The role of QS molecules in biofilm formation and their mechanism of action are complicated and it is assumed that besides chemical, physical, and nutritional factors there are some more factors and molecules that can influence this interaction. $^{10}$

\subsection{Cytotoxicity of Armillaria mellea methanolic extract}

Up to $400 \mu \mathrm{g} \mathrm{mL}{ }^{-1}$, the extract did not show any cytotoxicity for the tested human tumor cell lines (MCF7, NCI-H460, HCT-15 and HepG2). However, the methanolic extract did not show toxicity for non-tumor liver primary cells (PLP2; $\mathrm{GI}_{50}>$ $400 \mathrm{mg} \mathrm{mL}^{-1}$ ), which is a positive aspect. Our literature survey indicates that armillarikin and armillaridin, compounds isolated from the ethanolic extract of the A. mellea mycelium, presented significant cytotoxic potential against Huh 7, HepG2 and HA22 T cell lines. ${ }^{50}$

\section{Conclusion}

A detailed analysis of certain groups of compounds indicates that A. mellea is a rich source of bioactive molecules with potent in vitro bioactivities. According to the chemical composition and biological properties of $A$. mellea, this honey mushroom might be further explored to be used as a medicinal mushroom. Nevertheless, it is important to perform more studies on the different mechanisms of action involved and on the relationship with specific bioactive compounds present in this species.

\section{Acknowledgements}

The authors are grateful to the Serbian Ministry of Education, Science and Technological Development, grant number 173032 for financial support. The authors are also grateful to the Foundation for Science and Technology (FCT, Portugal) 
and FEDER under Programme PT2020 for financial support to CIMO (UID/AGR/00690/2013) and L. Barros contract.

\section{References}

1 V. Lobo, A. Patil, A. Phatak and N. Chandra, Free radicals, antioxidants and functional foods: Impact on human health, Pharmacogn. Rev., 2010, 4, 118-126.

2 F. Souilem, Â. Fernandes, R. C. Calhelha, J. C. M. Barreira, L. Barros, F. Skhiri, A. Martins and I. C. F. R. Ferreira, Wild mushrooms and their mycelia as sources of bioactive compounds: antioxidant, anti-inflammatory and cytotoxic properties, Food Chem., 2017, 230, 40-48.

3 M. L. Gargano, L. J. L. D. van Griensven, O. S. Isikhuemhen, U. Lindequist, G. Venturella, S. P. Wasser and G. I. Zervakis, Medicinal mushrooms: Valuable biological resources of high exploitation potential, Plant Biosyst., 2017, 151, 548-565.

4 C. V. Toledo, C. Barroetaveña, Â. Fernandes, L. Barros and I. C. F. R. Ferreira, Chemical and Antioxidant Properties of Wild Edible Mushrooms from Native Nothofagus spp. Forest, Argentina, Molecules, 2016, 21, 1201, DOI: 10.3390/ molecules2109120.

5 M. Soković, A. Ćirić, J. Glamočlija and D. Stojković, in Wild Plants, Mushrooms and Nuts: Functional Food Properties and Applications, ed. I. C. F. R. Ferreira, P. Morales and L. Barros, Wiley-Blackwell, UK, 1st edn, 2017, vol. 4, pp. 83-122.

6 P. Roupas, J. Keogh, N. Noakes, C. Margetts and P. Taylor, The role of edible mushrooms in health: Evaluation of the evidence, J. Funct. Foods, 2012, 4, 687-709.

7 J. Petrović, J. Glamočlija, D. Stojković, M. Nikolić, A. Ćirić, A. Fernandes, I. C. F. R. Ferreira and M. Soković, Bioactive composition, antimicrobial activities and the influence of Agrocybeaegerita, (Brig.) Sing on certain quorum-sensingregulated functions and biofilm formation by Pseudomonas aeruginosa, Food Funct., 2014, 5, 3296-3303.

8 S. Favre-Bonté, E. Chamot, T. Köhler, J. A. Romand and C. Van Delden, Autoinducer production and quorum sensing dependent phenotypes of Pseudomonas aeruginosavary according to isolation site during colonization of incubated patients, BMC Microbiol., 2007, 7, 33.

9 M. B. Miller and B. L. Bassler, Quorum sensing in bacteria, Annu. Rev. Microbiol., 2001, 55, 165-199.

10 Y.-H. Li and X. Tian, Quorum Sensing and Bacterial Social Interactions in Biofilms, Sensors, 2012, 12, 25192538.

11 G. Sharma, S. Rao, A. Bansal, S. Dang, S. Gupta and R. Gabrani, Pseudomonas aeruginosa biofilm: Potential therapeutic targets, Biologicals, 2014, 42, 1-7.

12 A. Y. Peleg and D. C. Hooper, Hospital-acquired infections due to Gram-negative bacteria, N. Engl. J. Med., 2010, 362, 1804-1813.

13 C. Lee Ventola, The Antibiotic Resistance Crisis Part 1: Causes and Threats, Pharm. Ther., 2015, 40, 277-283.
14 F. L. Mayer, D. Wilson and B. Hube, Candida albicans pathogenicity mechanisms, Virulence, 2013, 4, 119-128.

15 J. C. O. Sardi, L. Scorzoni, T. Bernardi, A. M. Fusco-Almeida and M. J. S. Mendes Giannini, Candida species: current epidemiology, pathogenicity, biofilm formation, natural antifungal products and new therapeutic options, J. Med. Microbiol., 2013, 62, 10-24.

16 WHO, Antimicrobial resistance, Global Reporton Surveillance, Antifungal drug resistance: the example of invasive Candidiasis, 2014, vol. 5, 62-65.

17 S. A. Heleno, L. Barros, A. Martins, P. Morales, V. Fernández-Ruiz, J. Glamoclija, M. Sokovic and I. C. F. R. Ferreira, Nutritional value, bioactive compounds, antimicrobial activity and bioaccessibility studies with wild edible mushrooms, LWT-Food Sci. Technol, 2015, 63, 799806.

18 O. Taofiq, R. C. Calhelha, S. Heleno, L. Barros, A. Martins, C. Santos-Buelga, M. J. R. P. Queiroz and I. C. F. R. Ferreira, The contribution of phenolic acids to the anti-inflammatory activity of mushrooms: screening in phenolic extracts, individual parent molecules and synthesized glucuronated and methylated derivatives, Food Res. Int., 2015, 76, 821827.

19 S. Zhang, X. Liu, L. Yan, Q. Zhang, J. Zhu, N. Huang and Z. Wang, Chemical Compositions and Antioxidant Activities of Polysaccharides from the Sporophores and Cultured Products of Armillariamellea, Molecules, 2015, 20, 5680-5697.

20 P. Roberts and S. Evans, The Book of Fungi: A Life-Size Guide to Six Hundred Species from around the World, University of Chicago Press, Chicago, IL, USA, 2011, p. 63.

21 K. M. J. de Mattos-Shipley, K. L. Ford, F. Alberti, A. M. Banks, A. M. Bailey and G. D. Foster, The good, the bad and the tasty: The many roles of mushrooms, Stud. Mycol., 2016, 85, 125-157.

22 D. E. Zavastin, C. Mircea, A. C. Aprotosoaie, S. Gherman, M. Hancianuand and A. Miron, Armillariamellea: phenolic content, in vitro antioxidant and antihyperglycemic effects, Rev. Med.-Chir. Soc. Med. Nat. Iasi, 2015, 119, 273-280.

23 AOAC, AOAC Official Methods of Analysis, AOAC International, 20th edn, 2016.

24 L. Barros, T. Cruz, P. Baptista, L. M. Estevinho and I. C. F. R. Ferreira, Wild andcommercial mushrooms as source of nutrients and nutraceuticals, Food Chem. Toxicol., 2008, 46, 2742-2747.

25 L. Barros, C. Pereira and I. C. F. R. Ferreira, Optimized analysis of organic acids in edible mushrooms from Portugal by ultra-fast liquid chromatography and photodiode array detection, Food Anal. Methods, 2013, 6, 309-316.

26 S. M. Bessada, J. C. M. Barreira, L. Barros, I. C. F. R. Ferreira and M. B. P. P. Oliveira, Phenolic profile and antioxidant activity of Coleostephusmyconis (L.) Rchb. f.: An underexploited and highly disseminated species, Ind. Crops Prod., 2016, 89, 45-51.

27 S. A. Heleno, L. Barros, M. J. Sousa, A. Martins and I. C. F. R. Ferreira, Tocopherols composition of Portuguese 
wild mushrooms with antioxidant capacity, Food Chem., 2010, 119, 1443-1450.

28 F. S. Reis, A. Martins, L. Barros and I. C. F. R. Ferreira, Antioxidant properties and phenolic profile of the most widely appreciated cultivated mushrooms: a comparative study between in vivo and in vitro samples, Food Chem. Toxicol., 2012, 50, 1201-1207.

29 F. S. Reis, S. A. Heleno, L. Barros, M. J. Sousa, A. Martins, C. Santos-Buelga and I. C. F. R. Ferreira, Toward the antioxidant and chemical characterization of mycorrhizal mushrooms from northeast Portugal, J. Food Sci., 2011, 76, 824-830.

30 A. Espinel-Ingroff, A comparasion of the E-test with the NCCLS M38-P method for antifungal susceptibility testing of common and emerging pathogenic filamentous fungi, J. Clin. Microbiol., 2001, 39, 1360-1367.

31 CLSI, Clinical and Laboratory Standards Institute, Methods for dilution antimicrobial susceptibility tests for bacteria that grow aerobically, Approved standard, 8th ed., CLSI publication M07-A8, Clinical and Laboratory Standards Institute, Wayne, PA, 2009.

32 E. Drenkard and F. M. Ausubel, Pseudomonas biofilm formationand antibiotic resistance are linked to phenotypicvariation, Nature, 2002, 416, 740-743.

33 A. L. Spoering and K. Lewis, Biofilms and planktonic cellsof Pseudomonas aeruginosa have similar resistance tokilling of antimicrobials, J. Bacteriol., 2001, 183, 67466751.

34 G. A. O'Toole and R. Kolter, Initiation of biofilm formationinPseudomonas fluorescens WCS365 proceeds via multiple, convergent signalling pathways: a genetic analysis, Mol. Microbiol., 1998, 28, 449-461.

35 Y. S. Siew-Mian and T. Foong-Yee, Anti-quorumsensing and antimicrobial activities of some traditional Chinese medicinal plants commonly used in South-East Asia, Malays. J. Microbiol., 2012, 8, 11-20.

36 D. W. Essar, L. Eberly, A. Hadero and I. Crawford, Identification and characterization of genes for a secondanthranilate synthase in Pseudomonas aeruginosa: Interchangeabilityof the two anthranilate synthases and evolutionaryimplications, J. Bacteriol., 1990, 172, 884-900.

37 A. Monks, D. Scudiero, P. Skehan, R. Shoemaker, K. Paull, D. Vistica, C. Hose, J. Langley, P. Cronise and A. VaigroWolff, Feasibility of a high-flux anticancer drug screen using a diverse panel of cultured human tumor cell lines, J. Natl. Cancer Inst., 1991, 83, 757-766.

38 R. M. V. Abreu, I. C. F. R. Ferreira, R. C. Calhelha, R. T. Lima, M. H. Vasconcelos, F. Adega, R. Chaves and M. J. R. P. Queiroz, Anti-hepatocellular carcinoma activity using human HepG2 cells and hepatotoxicity of 6- substituted methyl 3-aminothieno[3,2-b]pyridine-2- carboxylate derivatives: In vitro evaluation, cell cycle analysis and QSAR studies, Eur. J. Med. Chem., 2011, 46, 5800-5806.
39 J. A. Vaz, L. Barros, A. Martins, C. Santos-Buelga, M. H. Vasconcelos and I. C. F. R. Ferreira, Chemical composition of wild edible mushrooms andantioxidant properties of their water soluble polysaccharidicand ethanolic fractions, Food Chem., 2011, 126, 610-616.

40 B. Muszyńska and K. Ziaja, Chemical, Pharmacological, and Biological Characterization of the Culinary-Medicinal Honey Mushroom, Armillariamellea (Vahl) P. Kumm. (Agaricomycetideae): A Review, Int. J. Med. Mushrooms, 2011, 13, 167-175.

41 S. A. Heleno, R. C. Ferreira, A. L. Antonio, M. J. R. P. Queiroz, L. Barros and I. C. F. R. Ferreira, Nutritional value, bioactive compounds and antioxidant properties of three edible mushrooms from Poland, Food Biosci., 2015, 11, 48-55.

42 F. Kalyoncu, M. Oskay, H. Saglam, T. F. Erdogan and A. U. Tamer, Antimicrobial and Antioxidant Activities of Mycelia of 10 Wild Mushroom Species, J. Med. Food, 2010, 13, 415-419.

43 V. Kareiviene, A. Pavilonis, G. Sinkute, S. Liegiūte and G. Gailiene, Staphylococcus aureus resistance to antibiotics and spread of phage types, Medicina, 2006, 42, 332339.

44 E. B. Hirsch and V. H. Tam, Impact of multidrug-resistant Pseudomonas aeruginosa infection on patient outcomes, Expert Rev. Pharmacoecon. Outcomes Res., 2010, 10, 441451.

45 M. J. Alves, I. C. F. R. Ferreira, J. Dias, V. Teixeira, A. Martins and M. Pintado, A review on antimicrobial activity of mushroom (Basidiomycetes) extracts and isolated compounds, Planta Med., 2012, 78, 1707-1718.

46 P. G. Barranco, L. G. Ocanas, L. V. Cabrera, M. C. SalinasCarmona, F. G. Ocanas, X. S. Ramírez Gomez and R. L. Rangel, Evaluation of antioxidant, immunomodulating, cytotoxic and antimicrobial properties of differentstrains of Basidiomycetes from Northeastern Mexico, J. Med. Plants Res., 2010, 4, 1762-1769.

47 J. Henrichsen, Bacterial surface translocation: a survey and a classification (Review), Bacteriol. Rev., 1972, 36, 478503.

48 G. A. O'Toole and R. Kolter, Flagellar and twitching motility are necessary for Pseudomonas aeruginosa biofilm development, Mol. Microbiol., 1998, 30, 295-304.

49 S. Hall, C. McDermott, S. Anoopkumar-Dukie, A. J. McFarland, A. Forbes, A. V. Perkins, A. K. Davey, R. Chess-Williams, M. J. Kiefel, D. Aroraand and G. D. Grant, Cellular Effects of Pyocyanin, a Secreted Virulence Factor of Pseudomonas aeruginosa, Toxins, 2016, 8, 236.

50 Y. J. Chen, C. C. Chen and H. L. Huang, Induction of apoptosis by Armillariamelleaconstituent armillarikin in human hepatocellular carcinoma, OncoTargets Ther, 2016, 9, 4773-4783. 